\title{
Utilizing a Minimum of Four Antenatal Care Visits and Associated Factors in Debre Berhan Town, North Shewa, Amhara, Ethiopia, 2020
}

This article was published in the following Dove Press journal: Risk Management and Healthcare Policy

\section{Michael Amera Tizazu Eyosiyas Yeshialem Asefa (DD Mikyas Arega Muluneh (D) Asalif Beyene Haile}

Department of Midwifery, Health Science College, Debre Berhan University, Debre Berhan, Ethiopia
Correspondence: Eyosiyas Yeshialem

Asefa

Department of Midwifery, Health Science College, Debre Berhan University, Debre Berhan, Ethiopia

Tel +25I 913836869

Email eyosil43@gmail.com
Background: Receiving a minimum of four antenatal care, as per the World Health Organization recommendation, enhances the possibility of utilizing effective maternal health care during antenatal follow-up. Hence, this study aimed to identify the level of a minimum of 4 ANC usage and factors associated with Debre Berhan town.

Methods: A community-based cross-sectional study was employed from February 20 to March 10/2020 among women who gave birth in the last 6 months before the data collection period in Debre Berhan town. Data were collected using face-to-face interviews with the pretested tool by trained data collectors from randomly selected participants. After entering the data into Epi-data software version 3.1, it was further processed using SPSS version 23 statistical package. Both bivariate and multivariable Logistic regressions were fitted to identify the determinants for the utilization of a minimum of 4 antenatal care. A significance level of 0.05 was used to decide the significance of statistical tests.

Results: A total of 390 women were interviewed giving a response rate of $99.2 \%$. In this study, 78.5\% (95\% CI: 74.4-82.6) of women received a minimum of four antenatal care visits. Maternal educational status, initiation of antenatal visit at $\leq 16$ weeks of gestation, and husband support/partner involvement were identified predictors of utilization of minimum 4 antenatal visits.

Conclusion and Recommendations: Use of at least four antenatal visits in Debre Berhan town was found to be good. Health promotion programs targeting mothers with no education and lower educational level are important to increase their awareness about the importance of antenatal services. Male partner involvement during care related to pregnancy and promoting early initiation of antenatal care is important to overcome challenges towards a minimum of 4 antenatal visits in Debre Berhan town.

Keywords: minimum four antenatal, utilization, Ethiopia

\section{Background}

Antenatal care (ANC) is routine care given by a trained health care provider for a woman during pregnancy starting from the time of conception up to the delivery of the baby. ANC from trained health care providers is important to monitor pregnancy and to reduces complications and risks for the mother and child during pregnancy, delivery, and after giving birth. ${ }^{1,2}$

Although significant progress has been made in the last two decades, about 295 000 women died during and following pregnancy and childbirth in 2017. About 810 Women approximately die every day from preventable causes related to pregnancy 
and childbirth and $94 \%$ of all maternal deaths occur in low and lower-middle-income countries. ${ }^{3}$

Pregnancy-related preventable morbidity and mortality remain one of the global most critical challenges irrespective of significant progress and ambitions to end by 2030 . The world will face difficulties to achieve this target by more than one million lives with the current pace of progress. ${ }^{1,4,5}$

The world health organization (WHO) visions a world where each pregnant woman and newborn accessed quality care throughout the whole stage of pregnancy. ANC gives a platform for significant health care functions including, screening and diagnosis, health promotion, and disease prevention. Implementing important evidencebased practices on time, ANC can improve lives and provides the chance to communicate with and support pregnant women, families, and societies at an important time in the course of a woman's life., ${ }^{4,6}$

Antenatal care can support women making ready for delivery and understand danger signs during pregnancy and childbirth. It can be a source of micronutrient provision, care of hypertension to prevent eclampsia, tetanus immunization, and prevention of mother-to-child transmission of HIV/AIDS. In the malaria-endemic area, the health care provider can also give medication insecticide-treated mosquito nets to a pregnant woman. ${ }^{1,6,7}$

Globally, about $86 \%$ of pregnant women access antenatal care from trained health personnel at least once, but only two in three $(65 \%)$ receive at least four antenatal visits. In Sub-Saharan Africa and South Asia, about half of them received at least four antenatal visits $(52 \%$ and 48\%) respectively. ${ }^{6}$ The Ethiopian Min Demographic and Health Survey (EMDHS) showed that four in 10 women (43\%) had four or more ANC visits for their recent live births. Antenatal care coverage has increased in Ethiopia, from $28 \%$ in 2005 to $74 \%$ during 2019 . $^{2,8-10}$

Place of residence, region, mothers' education level, household wealth index, desire for pregnancy, frequency of reading newspaper, frequency of listening to the radio, and frequency of watching TV was associated with the utilization of a minimum of four ANC services. ${ }^{11,12}$

Unlike other parts of the world, there is no available data about the level of at least 4 ANC utilization and related factors in our study area. Therefore; this study was aimed to determine the level and factors associated with the utilization of a minimum of four antenatal care services in Debre Berhan town in 2020.

\section{Methods}

\section{Study Area}

The study was conducted in Debre Birhan town, located in the North Shewa Zone of Amhara region, 130 kilometers far from the capital city, Addis Ababa. According to the 2019 report of Debre Berhan Town administration's mayor office, the Town consists of nine kebeles (the smallest administrative unit) with an estimated total population of 114,652 (Male=51,843 and Female=62,809). Of the 62,809 female population, 39,066 were within the age group of 15-49 years. The town has four public (one referral hospital and three health centers) and three private health institutions. All the above health institutions had maternal health services. Health extension workers are community health workers responsible for identifying and registering all pregnant women at a time in their respective kebeles additional to the provision of tasks related to maternal health like provision of antenatal care, clean and safe deliveries, postnatal care, family planning, immunization and nutritional advice. ${ }^{13}$ According to the health extension worker's report; a total of 771 women gave birth in the last 6 months in Debre Berhan town.

\section{Study Design and Period}

A cross-sectional study at the community level study was conducted from February 20 to March 10/2020 among individuals randomly selected from the registration list of health extension workers.

\section{Source Population}

The source population for this study was all women who gave birth in the last 6 months before the data collection period in Debre Berhan town.

\section{Study Population}

This study was done on randomly selected women who gave birth in the last 6 months in Debre Berhan town. Women who reside less than six months at the study area during the time of data collection and who were unable to respond during data collection were excluded from the study.

\section{Sample Size Determination}

The sample size for this study was calculated using the assumptions for single population proportion with estimated proportion of completion of at least four antenatal care $36.6 \%$ from a cross-sectional study which was 
analyzed from the 2016 Ethiopian Demographic and Health Survey (EDHS) data, ${ }^{11}$ confidence level of 95\%, $5 \%$ degree of precision, and 10\% non-response rate, using the following formula.

$$
\mathrm{n}=\frac{Z_{a / 2}^{2} p(1-p)}{d^{2}}
$$

Where,

$\mathrm{n}=$ sample size,

$\mathrm{Z}_{\mathrm{a} / 2}=$ the value under the normal standard table for the given confidence level,

$\mathrm{p}=$ estimated of the population proportion,

$\mathrm{d}=$ margin of error, by using the above equation the sample size was calculated as follows:

$$
n=\frac{(1.96)^{2} * 0.366(1-0.366)}{(0.05)^{2}}
$$

$\mathrm{n}=356.568 \sim 357$ by considering the non-response rate the last sample included became 393.

\section{Sampling Technique}

We found a total of 771 women who gave birth in the last 6 months from the registry book. Then after excluding those using the exclusion criteria we reached 769 women as a frame. Finally, we selected a total of 393 samples to be included in this study using the lottery method.

\section{Data Collection methods and Procedures}

Data was collected using the interviewer guide pre-tested tool using trained $2 \mathrm{BSc}$ midwives data collectors and one MSc midwife as a supervisor. The data collection questionnaire was adapted from the Ethiopian Demographic and Health Survey (EDHS) and other literature. The tool incorporates socio-demographic variables, obstetrics related variables, and maternal health service-related variables. The data collectors and supervisors accessed the house of study subjects with the help of health development army (HDA) leaders.

\section{Variables}

\section{Dependent Variable}

"Utilization of a minimum of 4 ANC services"

\section{Explanatory Variables}

Socio-demographic (age, marital status, educational status, occupation, monthly income), reproductive and obstetrics related (number of pregnancy, planned/unplanned pregnancy, number of children, number of ANC visit, months of first ANC visit) and maternal health care service-related (counseling on pregnancy complication, birth preparedness, performing urinalysis and blood checkups during ANC, TT vaccination).

\section{Operational Definitions}

Antenatal care utilization (at least four visits): utilization of at least 4 antenatal care visits of a woman of reproductive age group with a live birth during her pregnancy time. ${ }^{1,6}$

Birth preparedness: Well prepared for birth and its complications were considered when women reported that they have implemented five or more components of birth preparedness and complication readiness (BPCR) otherwise considered as "not well prepared". The components of BPCR considered in this study were identified birthplace, identified sign of labor, identify supplies needed during labor/delivery, saving money for an emergency, identified emergency transportation, people to support during/after birth, and identified potential blood donors as needed. ${ }^{14}$

Planned pregnancy: is only if they had met four key criteria. Intending to become pregnant, stopping contraception, partner agreement, and reaching the right time in terms of lifestyle/life stage were also necessary. ${ }^{15}$

Partner support: measured if one of the following three criteria were practiced. Reminded his partner's ANC follow-up schedule; covered medical/transport costs of partner's ANC follow-up accompanied partner to ANC clinic at least once.

\section{Data Quality Assurance}

A one-day training was given for data collectors and supervisors on the objective of the study, and the content of the tool. Back and forth questionnaire translation was done to check its consistency with the original meaning. Before commencing data collection, a pre-test was conducted among $10 \%$ of the study sample and, the required adjustments were made on unclear questions. Additionally, we did a reliability test and we found Cronbach's alpha (reliability coefficient) equals 0.78 showings acceptable level of consistencies. Daily meetings and supervision were performed throughout the data collection period.

\section{Data Processing and Analysis}

After Checking the completeness and consistency, the collected data were coded and entered into Epi-data software version 3.1 and then exported to SPSS version 23 statistical package for analysis. Descriptive statistics were done to 
quantify the use of at least 4 ANC visits and other characteristics. Variables with a $P$ value of less than 0.25 on bivariate logistic regression were selected as a candidate for multivariate logistic regression. Finally, multivariable Logistic regressions were used to assess the relative impact of explanatory variables on dependent variables and to select important predictors of at least 4 ANC visits. The fitness of the model was measured by Hosmer and Lemeshow goodness of test and multicollinearity between the independent variables was checked by the variance inflation factor (VIF $>10$ ). Adjusted Odds Ratio (AOR) and their 95\% Confidence Interval (CI) was used to determine the level of association. A significance level of 0.05 was used to declare the significance of statistical tests. Finally, the finding was presented using narration and tables.

\section{Ethical Consideration}

A letter of Ethical clearance was secured from the Institutional Review Board (IRB) of health Science College, Debre Berhan University. A formal letter of permission was obtained from the Debre Berhan town health office. Informed written consent was obtained from study subjects. Additionally, after doing the witness attests that the consent information was accurately explained for those who cannot read and write, that the subject apparently understood the information, and informed consent was given freely. Participants had the right to self-determination regarding participation in research, both initially and during the research. For confidentiality purposes, the names of the participant were not included in the questionnaire. The collected data were kept confidential and used only for the study. This study was conducted following the Declaration of Helsinki.

\section{Results}

\section{Socio-Demographic Characteristics of the Study Participants}

From a total of 393 participants, 390 were interviewed. The majority $269(69 \%)$ of respondents were aged 25-34 years and the mean age was $28.9 \pm 4.55$ years. Most women 370 (94.9\%) were married. While $37(9.5 \%)$ had no education, 167 (42.8\%) had college and above education. Almost 97\% of study participants were Amhara by ethnicity. Nearly half (48.3\%) were housewives. Most women 349 (89.5\%) were ever heard about maternal health services. Over half 209 (53.6\%) of participant's partners attained tertiary education (college and above). By occupation, 158 (40.5\%) of their partner were government employee (Table 1).
Table I Socio-Demographic Characteristics of the Study Participants in Debre Berhan Town, Ethiopia 2020 ( $n=390)$

\begin{tabular}{|c|c|c|c|}
\hline \multicolumn{2}{|l|}{ Characteristics } & \multirow{2}{*}{$\begin{array}{l}\text { Frequency } \\
65 \\
269 \\
56\end{array}$} & \multirow{2}{*}{$\begin{array}{l}\text { Percentage } \\
16.7 \\
69.0 \\
14.4\end{array}$} \\
\hline $\begin{array}{l}\text { Age of women in } \\
\text { years }\end{array}$ & $\begin{array}{l}19-24 \\
25-34 \\
\geq 35\end{array}$ & & \\
\hline Religion & $\begin{array}{l}\text { Orthodox } \\
\text { Muslim } \\
\text { Protestant } \\
\text { Others }\end{array}$ & $\begin{array}{l}342 \\
18 \\
26 \\
4\end{array}$ & $\begin{array}{l}87.8 \\
4.6 \\
6.7 \\
1.0\end{array}$ \\
\hline Ethnicity & $\begin{array}{l}\text { Amhara } \\
\text { Oromo } \\
\text { Tigre } \\
\text { Guragie } \\
\text { Others }\end{array}$ & $\begin{array}{l}378 \\
3 \\
2 \\
5 \\
2\end{array}$ & $\begin{array}{l}96.9 \\
0.8 \\
0.5 \\
1.3 \\
0.5\end{array}$ \\
\hline Marital status & $\begin{array}{l}\text { Married } \\
\text { Divorced/separated } \\
\text { Widowed } \\
\text { Single }\end{array}$ & $\begin{array}{l}370 \\
16 \\
1 \\
3\end{array}$ & $\begin{array}{l}94.9 \\
4.1 \\
0.3 \\
0.8\end{array}$ \\
\hline Educational status & $\begin{array}{l}\text { No education } \\
\text { Primary education }{ }^{1-8} \\
\text { Secondary } \\
\text { education } \\
\text { College and above }\end{array}$ & $\begin{array}{l}37 \\
125 \\
61 \\
167\end{array}$ & $\begin{array}{l}9.5 \\
32.1 \\
15.6 \\
42.8\end{array}$ \\
\hline Occupation & $\begin{array}{l}\text { Farmer } \\
\text { Housewives } \\
\text { Private employed } \\
\text { Gov't employed } \\
\text { Merchant } \\
\text { Others }\end{array}$ & $\begin{array}{l}4 \\
9 \\
188 \\
46 \\
107 \\
29 \\
7\end{array}$ & $\begin{array}{l}1.0 \\
2.3 \\
48.2 \\
11.8 \\
27.4 \\
7.4 \\
1.8\end{array}$ \\
\hline $\begin{array}{l}\text { Family monthly } \\
\text { income(ETB) }\end{array}$ & $\begin{array}{l}\leq 500 \\
50|-| 500 \\
|50|-2500 \\
\geq 250 \mid\end{array}$ & $\begin{array}{l}7 \\
23 \\
49 \\
311\end{array}$ & $\begin{array}{l}1.8 \\
5.9 \\
12.6 \\
79.7\end{array}$ \\
\hline $\begin{array}{l}\text { Educational status of } \\
\text { partner }\end{array}$ & $\begin{array}{l}\text { No education } \\
\text { Primary education }{ }^{1-8} \\
\text { Secondary } \\
\text { education } \\
\text { College and above }\end{array}$ & $\begin{array}{l}37 \\
46 \\
98 \\
209\end{array}$ & $\begin{array}{l}9.5 \\
11.8 \\
25.1 \\
\\
53.6\end{array}$ \\
\hline $\begin{array}{l}\text { Occupation of } \\
\text { partner }\end{array}$ & $\begin{array}{l}\text { Farmer } \\
\text { Private employed } \\
\text { Gov't employed } \\
\text { Merchant } \\
\text { Daily laborer } \\
\text { Others }\end{array}$ & $\begin{array}{l}20 \\
100 \\
158 \\
70 \\
27 \\
15\end{array}$ & $\begin{array}{l}5.1 \\
25.6 \\
40.5 \\
17.9 \\
6.9 \\
3.8\end{array}$ \\
\hline $\begin{array}{l}\text { Ever Heard } \\
\text { maternal health } \\
\text { services }\end{array}$ & $\begin{array}{l}\text { Yes } \\
\text { No }\end{array}$ & $\begin{array}{l}349 \\
41\end{array}$ & $\begin{array}{l}89.5 \\
10.5\end{array}$ \\
\hline $\begin{array}{l}\text { Source of maternal } \\
\text { health information } \\
(n=349)\end{array}$ & $\begin{array}{l}\text { Mass-media(tv/radio) } \\
\text { Health care provider } \\
\text { Others }\end{array}$ & $\begin{array}{l}122 \\
214 \\
13\end{array}$ & $\begin{array}{l}35.0 \\
61.3 \\
3.7\end{array}$ \\
\hline
\end{tabular}




\section{Reproductive and Maternal Health}

Services-Related Characteristics of Study

\section{Participants}

Among study participants, 140 (35.9\%) had their first pregnancy, whereas, $41(10.5 \%)$ had four and more pregnancies. Almost $97 \%$ of the participant's recent pregnancy was planned. Three hundred thirty-seven $(86.4 \%)$ of women had initiated their first antenatal visit at or less than 16 weeks of gestation and 306 (78.5\%) had four or more antenatal visits throughout their pregnancy. Out of all respondents, 228 (58.5\%) of women had received their antenatal care at public health centers. Nearly $90 \%$ had their husband's support during maternal health care visit. Regarding the services provided during the pregnancy period; 378 (96.9\%) had blood pressure measurement, $370(94.9 \%)$ received nutritional counseling, 260 (66.7\%) had taken vaccination for tetanus, 359 (92.1\%) informed about danger signs, $352(90.3 \%)$ counseled about birth preparedness and complication readiness plan and 353 $(90.5 \%)$ had received iron and folate (Table 2).

\section{Factors Associated with the Utilizing a Minimum of 4 Antenatal Visits}

This study identified some important factors that are associated with the utilization of a minimum of 4 ANC visits in Debre Berhan town. Maternal educational status, initiation of ANC visit $\leq 16 \mathrm{wks}$ of gestation, and husband support/partner involvement were statistically significant association with the outcome variable.

The odds of utilization of a minimum of 4 ANC visits were three times higher among women who had college and above education (AOR: 3.09 , 95\% CI: 1.16-8.27) than those who had no education. The odds of utilization of minimum 4 ANC visits was eight times higher for those who had first ANC visit at $\leq 16$ weeks of gestation than their counterparts (AOR: 8.30, 95\% CI: 4.01-17.18). Similarly, The odds of utilization of a minimum of 4 ANC visits were two times higher for those who had husband support than their counterparts (AOR: 2.28, 95\% CI: 1.03-5.06)(Table 3).

\section{Discussion}

The result of the study revealed that the utilization of a minimum of four ANC visits was 78.5\% (95\% CI: 74.4-82.6) in Debre Berhan town. This value was greater than the finding of previous studies in Ethiopia 33\%, ${ }^{16}$ $36.2 \%,{ }^{11}$ and $36.78 \% .{ }^{17}$ This could be because; previous studies were conducted in both urban and rural settings,
Table 2 Reproductive and Maternal Health Services-Related Characteristics of the Study Participants in Debre Berhan Town Ethiopia $2020(n=390)$

\begin{tabular}{|c|c|c|c|}
\hline \multicolumn{2}{|l|}{ Characteristics } & \multirow{4}{*}{$\begin{array}{l}\text { Frequency } \\
140 \\
209 \\
41\end{array}$} & \multirow{4}{*}{$\begin{array}{l}\text { Percentage } \\
35.9 \\
53.6 \\
10.5\end{array}$} \\
\hline Number of pregnancy & 1 & & \\
\hline & $2-3$ & & \\
\hline & $\geq 4$ & & \\
\hline \multirow[t]{2}{*}{ Pregnancy planned } & Yes & 378 & 96.9 \\
\hline & No & 12 & 3.1 \\
\hline \multirow[t]{3}{*}{ Number of children } & 1 & 142 & 36.4 \\
\hline & $2-3$ & 213 & 54.6 \\
\hline & $\geq 4$ & 35 & 9.0 \\
\hline \multirow{2}{*}{$\begin{array}{l}\text { Number of ANC visit } \\
\text { for the last pregnancy }\end{array}$} & $<4$ & 84 & 21.5 \\
\hline & $\geq 4$ & 306 & 78.5 \\
\hline \multirow{2}{*}{$\begin{array}{l}\text { Timing of first ANC visit } \\
\text { for the last pregnancy }\end{array}$} & $\leq 16$ weeks & 337 & 86.4 \\
\hline & $>16$ weeks & 53 & 13.6 \\
\hline \multirow[t]{5}{*}{ Place of ANC visit } & Gov't hospital & 109 & 27.9 \\
\hline & $\begin{array}{l}\text { Gov't health } \\
\text { center }\end{array}$ & 228 & 58.5 \\
\hline & Private & 30 & 7.7 \\
\hline & hospital & & \\
\hline & Private clinic & 23 & 5.9 \\
\hline \multirow[t]{2}{*}{ Partner support } & Yes & 345 & 88.5 \\
\hline & No & 45 & 11.5 \\
\hline \multirow{2}{*}{$\begin{array}{l}\text { Informed key pregnancy } \\
\text { danger signs }\end{array}$} & Yes & 359 & 92.1 \\
\hline & No & 31 & 7.9 \\
\hline \multirow{2}{*}{$\begin{array}{l}\text { Blood pressure } \\
\text { measured at ANC }\end{array}$} & Yes & 378 & 96.9 \\
\hline & No & 12 & 3.1 \\
\hline \multirow[t]{2}{*}{ Urine sample taken } & Yes & 368 & 94.4 \\
\hline & No & 22 & 5.6 \\
\hline \multirow[t]{2}{*}{ Blood sample taken } & Yes & 382 & 97.9 \\
\hline & No & 8 & 2.1 \\
\hline \multirow[t]{2}{*}{ Nutritional counseling } & Yes & 370 & 94.9 \\
\hline & No & 20 & 5.1 \\
\hline \multirow[t]{2}{*}{ TT vaccine at ANC } & Yes & 260 & 66.7 \\
\hline & No & 130 & 33.3 \\
\hline \multirow{2}{*}{$\begin{array}{l}\text { Number of TT vaccine } \\
(n=260)\end{array}$} & One & 87 & 33.5 \\
\hline & Two or more & 173 & 66.5 \\
\hline \multirow[t]{2}{*}{ Iron tablet taken } & Yes & 353 & 90.5 \\
\hline & No & 37 & 9.5 \\
\hline \multirow{2}{*}{$\begin{array}{l}\text { Deworming during } \\
\text { ANC }\end{array}$} & Yes & 140 & 90.5 \\
\hline & No & 250 & 9.5 \\
\hline \multirow{2}{*}{$\begin{array}{l}\text { Informed about Birth } \\
\text { preparedness plan }\end{array}$} & Yes & 352 & 90.3 \\
\hline & No & 38 & 9.7 \\
\hline \multirow{2}{*}{$\begin{array}{l}\text { Status of Birth } \\
\text { preparedness }\end{array}$} & Well prepared & 199 & 51.0 \\
\hline & $\begin{array}{l}\text { Not well } \\
\text { prepared }\end{array}$ & 191 & 49.0 \\
\hline
\end{tabular}


Table 3 Factors Associated with the Utilization of a Minimum 4 Antenatal Visits in Debre Berhan Town Ethiopia 2020 ( $\mathrm{n}=390$ )

\begin{tabular}{|c|c|c|c|c|}
\hline \multirow[t]{2}{*}{ Variables } & \multicolumn{2}{|c|}{ Utilization of Minimum 4 ANC } & \multirow[t]{2}{*}{ COR(95\% Cl) } & \multirow[t]{2}{*}{ AOR(95\% CI) } \\
\hline & Yes & No & & \\
\hline \multicolumn{5}{|c|}{ Educational status of the mother } \\
\hline No education & 21 & 16 & $\mathrm{I}$ & $\mathrm{I}$ \\
\hline Primary education & 92 & 33 & $2.124(0.991-4.553)$ & $1.89(0.788-4.524)$ \\
\hline Secondary educatior & 45 & 16 & $2.143(0.902-5.090)$ & $1.88(0.708-4.965)$ \\
\hline College and above & 148 & 19 & $5.935(2.648-13.300)$ & $3.79(1.539-9.35 I)^{*}$ \\
\hline \multicolumn{5}{|l|}{ Number of pregnancy } \\
\hline One & 115 & 25 & $2.385(1.097-5.188)$ & $\mathrm{I} .6 \mathrm{I}(0.567-4.562)$ \\
\hline Two-three & 164 & 45 & $1.890(0.915-3.901)$ & I.I8(0.459-3.0II) \\
\hline Four or more & 27 & 14 & 1 & I \\
\hline \multicolumn{5}{|c|}{ Was the pregnancy planned } \\
\hline Yes & 301 & 77 & $5.473(1.69|-| 7.715)$ & $2.08(0.440-9.85 \mathrm{I})$ \\
\hline No & 5 & 7 & 1 & 1 \\
\hline \multicolumn{5}{|c|}{ Timing of first ANC visit } \\
\hline$\leq 16$ weeks & 288 & 49 & $1 \mathrm{I} .429(6.00 \mathrm{I}-2 \mathrm{I} .764)$ & 8.87(4.478-I7.558)* \\
\hline$>16$ weeks & 18 & 35 & 1 & 1 \\
\hline \multicolumn{5}{|l|}{ Husband support } \\
\hline Yes & 283 & 62 & $4.366(2.289-8.329)$ & $2.29(1.076-4.877)^{*}$ \\
\hline No & 23 & 22 & 1 & 1 \\
\hline \multicolumn{5}{|c|}{ Informed key pregnancy danger signs } \\
\hline Yes & 288 & 71 & $2.930(1.37 \mid-6.259)$ & I.10(0.388-3.146) \\
\hline No & 18 & 13 & 1 & 1 \\
\hline \multicolumn{5}{|c|}{ Nutritional counseling during pregnancy } \\
\hline Yes & 293 & 77 & $2.049(0.790-5.311)$ & $1.17(0.318-4.318)$ \\
\hline No & 13 & 7 & 1 & 1 \\
\hline \multicolumn{5}{|c|}{ TT vaccination during pregnancy } \\
\hline Yes & 215 & 45 & $2.048(1.250-3.355)$ & $1.73(0.979-3.057)$ \\
\hline No & 91 & 39 & 1 & 1 \\
\hline \multicolumn{5}{|l|}{ Iron and folate taken } \\
\hline Yes & 286 & 67 & $3.628(1.803-7.300)$ & I.18(0.450-3.096) \\
\hline No & 20 & 17 & 1 & I \\
\hline \multicolumn{5}{|l|}{ Informed about BPCR } \\
\hline Yes & 281 & 71 & $2.058(1.003-4.224)$ & $1.29(0.519-3.224)$ \\
\hline No & 25 & 13 & 1 & I \\
\hline \multicolumn{5}{|l|}{ Status of BPCR } \\
\hline Well-prepared & 168 & 31 & $2.08 I(1.266-3.422)$ & $\mathrm{I} .45(0.840-2.676)$ \\
\hline Not well-prepared & 138 & 53 & I & I \\
\hline
\end{tabular}

Note: *p-value $<0.05$

which includes women with lower access to antenatal care visits but the current study was conducted in the urban areas. This explanation is maintained by previous studies conducted in Ethiopia, where urban women have better access to antenatal care than those women living in rural areas. $^{7,18}$ Similarly, utilization of at least 4 ANC visits in our study area was much higher than a study in Northern Ethiopia, ${ }^{19}$ Vietnam, ${ }^{20}$ Nigeria, ${ }^{21}$ and Timor-Leste. ${ }^{22}$ This discrepancy might be because of the difference in the study setting like time and study area (rural areas).

On the other hand, the finding was found to be lower than a study done in Ghana where About $95 \%$ of women 
had a minimum of four antenatal visits. ${ }^{23}$ This variation might be from the difference in sociodemographic variables between the study population.

The odds of usage of at least 4 ANC visits were higher among women with higher education compared to uneducated women. This finding was consistent with the findings of a prior study done in Ethiopia, ${ }^{11,16,18}$ and finding from Benin republic, ${ }^{24}$ Tanzania, ${ }^{25}$ Vietnam, ${ }^{20}$ and TimorLeste $^{22}$ which showed that being educated or having a higher level of education had a positive impact on increasing the chance of at least 4 ANC visits. The reason might be; education creates a better chance to access through different sources, understand and utilize pieces of information ${ }^{21}$ regarding maternal and child health care as well as a better understanding of the importance of completing ANC visits and the consequence of danger signs on pregnancy. It is also true that education helps the mothers to engage in different activities and programs that scale up their understanding of ANC services. ${ }^{7,26}$ A possible explanation also might be that educated women might have a better chance of having their income sources and autonomy to decide on maternal health-care seeking. This is also plausible with the fact that women's autonomy to decide on health care service utilization increases their ANC visits/coverage. ${ }^{17}$

Women who had an early antenatal visit were 9 times more likely to utilize a minimum of 4 ANC visits compared to late started women. This finding was found to be consistent with a study in Tanzania ${ }^{25}$ showing initiation of ANC after the first 4 weeks of pregnancy increases the chance of utilization of at least 4 ANC visits. Early antenatal care initiation is a key strategy to improve the utilization of maternal health care visits during pregnancy; WHO's recommendations to women attain adequate antenatal care visits. ${ }^{1}$ This might be due to early initiation helps the women to get early counseling about ANC visits schedules and establish a client-provider relationship, this, in turn, helps them to complete at least $4 \mathrm{ANC}$ visits.

The chance of completing $\geq 4$ ANC visits was higher among pregnant women who had their husbands support/ approval for antenatal visits compared to those counterparts. The above result was supported by a prior study done in Yem special wereda/district, Hadiya/South Ethiopia, Northern Ethiopia, ${ }^{19,27,28}$ Jayapura (Indonesia), ${ }^{29}$ and Vietnam. ${ }^{20}$ The possible reason might be due to women feels confident and increase their health-seeking behavior, these encourage them to attend more antenatal care visits. Women having a big problem in permission and support (not getting money) to visit health facility could have a lower number of the visit of ANC during pregnancy, ${ }^{22.21}$

On contrary; Number of pregnancy, Informed key pregnancy danger signs, TT vaccination during pregnancy, Iron and folate taken, Informed about Birth Preparedness Complication Readiness, and Status of Birth Preparedness Complication Readiness were those variables which were not significantly associated with utilization of at least 4 ANC visits in our study while these were found to have significant association on different studies. ${ }^{21,25}$ This discrepancy might be from the difference in the study setting.

\section{Conclusion and Recommendation}

The utilization of $4 \mathrm{ANC}$ visits in Debre Berhan town is better compared to the national data (43\%). Additionally; this study revealed that early initiation of ANC visits, male partner support, and higher educational level was significantly associated with the utilization of a minimum of 4 ANC services in Debre Berhan town. Promoting partner involvement during maternal health care services utilization and encouraging early initiation of first ANC visits are very important to scale up their utilization of at least 4 ANC services. In addition to increasing, universal access to education for women in the long run; Health promotion programs focusing on women with no education/lower educational status are important to increase their awareness about the importance of completing full antenatal services. Therefore, a collaboration of different stakeholders and an integrated effort should be applied to sustain the current positive outcome and to scale up the antenatal care service utilization.

\section{Abbreviations}

ANC, antenatal care; AOR, Adjusted Odds Ratio; BSc, Bachelor of Science; CI, Confidence Interval; COR, Crude Odds Ratio; AOR, adjusted odds ratio; SD, Standard Deviation; WHO, World Health Organization; SPSS- statistical package for social science; HSTP, Health sector transformation plan; HAD, health development army, RMNCAH, reproductive maternal newborn child and adolescent health; EDHS, Ethiopian demographic health survey; HIV, human immune-deficiency virus.

\section{Data Sharing Statement}

The data utilized to support the result of this study will be available from the corresponding author based on reasonable request. 


\section{Consent for Publication}

Not applicable

\section{Acknowledgment}

First of all, we would like to thank God for giving us the courage and wisdom to do our work. Then, we would like to mention and pass our acknowledgment to Debre Berhan University, friends, and colleagues. We finally thank data collectors and supervisors for their commitment during the data collection process.

\section{Author Contributions}

All authors made a significant contribution to the work reported, whether that is in the conception, study design, execution, acquisition of data, analysis, and interpretation, or in all these areas; took part in drafting, revising, or critically reviewing the article; gave final approval of the version to be published; have agreed on the journal to which the article has been submitted, and agree to be accountable for all aspects of the work.

\section{Funding}

The whole required (material and humanitarian) cost for this research work was covered by Debre Berhan University.

\section{Disclosure}

The authors of this paper declare that we have no conflict of interests.

\section{References}

1. WHO. WHO Recommendations on Antenatal Care for a Positive Pregnancy Experience. World Health Organization; 2016.

2. Institute EPH, ICF. Ethiopia Mini Demographic and Health Survey 2019: Key Indicators. Rockville, Maryland, USA: EPHI and ICF; 2019.

3. WHO. Maternal health global situation 2020 2020. Available from: https:// www.who.int/health-topics/maternal-health\#tab=tab_1. Accessed November 25, 2020.

4. WHO. Strategies Towards Ending Preventable Maternal Mortality (EPMM). World Health Organization; 2015.

5. WHO. Trends in Maternal Mortality 2000 to 2017: Estimates by WHO. UNICEF, UNFPA, World Bank Group and the United Nations Population Division; 2019.

6. UNICEF. UNICEF Data: Monitoring The Situation Of Children And Women," in 2e State of the World's Children Report. New York, NY, USA: UNICEF; 2019.

7. Yeneneh A, Alemu K, Dadi AF, Alamirrew A. Spatial distribution of antenatal care utilization and associated factors in Ethiopia: evidence from Ethiopian demographic health surveys. BMC Pregnancy Childbirth. 2018;18(1):1-12. doi:10.1186/s12884-018-1874-2
8. Agency CS, ICF. Ethiopia Demographic and Health Survey 2016: Key Indicators Report. Addis Ababa, Ethiopia, and Rockville, Maryland, USA: CSA and ICF; 2016.

9. Central Statistical Agency I. Ethiopia Demographic and Health Survey 2011: Key Indicators Report. Addis Ababa, Ethiopia, and Rockville, Maryland, USA: CSA and ICF; 2011.

10. Central Statistical Agency I. Ethiopia Demographic and Health Survey 2005: Key Indicators Report. Addis Ababa, Ethiopia, and Rockville, Maryland, USA: CSA and ICF; 2005.

11. Basha GW. Factors affecting the utilization of a minimum of four antenatal care services in Ethiopia. Obstet Gynecol Int. 2019;2019.

12. Tsegaye B, Ayalew M. Prevalence and factors associated with antenatal care utilization in Ethiopia: an evidence from demographic health survey 2016. BMC Pregnancy Childbirth. 2020;20(1):1-9. doi:10.1186/s12884-020-03236-9

13. Medhanyie A, Spigt M, Kifle Y, et al. The role of health extension workers in improving utilization of maternal health services in rural areas in Ethiopia: a cross sectional study. BMC Health Serv Res. 2012;12(1):352. doi:10.1186/1472-6963-12-352

14. Belda SS, Gebremariam MB. Birth preparedness, complication readiness and other determinants of place of delivery among mothers in Goba District, Bale Zone, South East Ethiopia. BMC Pregnancy Childbirth. 2016;16(1):73. doi:10.1186/s12884-016-0837-8

15. Barrett $\mathrm{G}$, Wellings $\mathrm{K}$. What is a 'planned'pregnancy? Empirical data from a British study. Soc Sci Med. 2002;55(4):545-557. doi:10.1016/ S0277-9536(01)00187-3

16. Muchie KF. Quality of antenatal care services and completion of four or more antenatal care visits in Ethiopia: a finding based on a demographic and health survey. BMC Pregnancy Childbirth. 2017;17(1):1-7. doi:10.1186/s12884-017-1488-0

17. Tegegne TK, Chojenta C, Getachew T, Smith R, Loxton D. Antenatal care use in Ethiopia: a spatial and multilevel analysis. $B M C$ Pregnancy Childbirth. 2019;19(1):399. doi:10.1186/s12884-0192550-x

18. Ousman SK, Mdala I, Thorsen VC, Sundby J, Magnus JH. Social determinants of antenatal care service use in Ethiopia: changes over a 15-year span. Front Public Health. 2019;7:161. doi:10.3389/ fpubh.2019.00161

19. Ftwi M, Gebretsadik GG-E, Berhe H, Haftu M, Gebremariam G, Tesfau YB. Coverage of completion of four ANC visits based on recommended time schedule in Northern Ethiopia: a community-based cross-sectional study design. PLoS One. 2020;15 (8):e0236965. doi:10.1371/journal.pone.0236965

20. Ha BT, Tac PV, Duc DM, Duong DT, Thi LM. Factors associated with four or more antenatal care services among pregnant women: a cross-sectional survey in eight south central coast provinces of Vietnam. Int $j$ Women's Health. 2015;7:699.

21. Adewuyi EO, Auta A, Khanal V, et al. Prevalence and factors associated with underutilization of antenatal care services in Nigeria: a comparative study of rural and urban residences based on the 2013 Nigeria demographic and health survey. PLoS One. 2018;13(5):e0197324. doi:10.1371/journal.pone.0197324

22. Khanal V, da Cruz JLNB, Mishra SR, Karkee R, Lee AH. Underutilization of antenatal care services in Timor-Leste: results from Demographic and Health Survey 2009-2010. BMC Pregnancy Childbirth. 2015;15(1):211. doi:10.1186/s12884-015-0646-5

23. Yeji F, Shibanuma A, Oduro A, et al. Continuum of care in a maternal, newborn and child health program in Ghana: low completion rate and multiple obstacle factors. PLoS One. 2015;10(12): e0142849. doi:10.1371/journal.pone.0142849

24. Dansou J, Adekunle AO, Arowojolu AO. Factors associated with antenatal care services utilisation patterns amongst reproductive age women in Benin Republic: an analysis of 2011/2012 Benin Republic's demographic and health survey data. Nigerian Postgrad Med J. 2017;24(2):67. doi:10.4103/npmj.npmj_16_17 
25. Gupta S, Yamada G, Mpembeni R, et al. Factors associated with four or more antenatal care visits and its decline among pregnant women in Tanzania between 1999 and 2010. PLoS One. 2014;9(7):e101893. doi:10.1371/journal.pone.0101893

26. Ayalew TW, Nigatu AM. Focused antenatal care utilization and associated factors in Debre Tabor Town, northwest Ethiopia, 2017. BMC Res Notes. 2018;11(1):819. doi:10.1186/s13104-0183928-y
27. Tewodros B, Dibaba Y. Factors affecting antenatal care utilization in Yem special woreda, southwestern Ethiopia. Ethiop J Health Sci. 2009;19:1.

28. Abosse Z, Woldie M, Ololo S. Factors influencing antenatal care service utilization in hadiya zone. Ethiop J Health Sci. 2010;20:2.

29. Kamo B, Msen Y, Rantetampang A, Mallongi A. The factors affecting with four visited at public health centre Sub Province Mimika Papuan Province. Education. 2018;76(11):6.

\section{Publish your work in this journal}

Risk Management and Healthcare Policy is an international, peerreviewed, open access journal focusing on all aspects of public health, policy, and preventative measures to promote good health and improve morbidity and mortality in the population. The journal welcomes submitted papers covering original research, basic science, clinical \& epidemiological studies, reviews and evaluations, guidelines, expert opinion and commentary, case reports and extended reports. The manuscript management system is completely online and includes a very quick and fair peer-review system, which is all easy to use. Visit http://www.dovepress.com/testimonials.php to read real quotes from published authors.

Submit your manuscript here: https://www.dovepress.com/risk-management-and-healthcare-policy-journal 